\title{
Subcutaneous apomorphine in the treatment of Parkinson's disease
}

\author{
J P Frankel, A J Lees, P A Kempster, G M Stern
}

\begin{abstract}
Apomorphine a dopamine receptor agonist was given subcutaneously to 57 levodopa treated parkinsonian patients with refractory off-period disabilities for a median period of 16 months. In 30 given intermittent suprathreshold injections the mean number of hours spent in a disabling off state fell from 6.9 to 2.9 . Similar benefit was observed in 21 patients receiving continuous infusions with additional boluses on demand by mini-pump (mean reduction of hours off from 9.9 to 4.5 ). Twelve patients have been treated for over two years without tachyphylaxis or loss of response. The incidence of neuropsychiatric sideeffects has been low (7\%). Six patients failed to show a sustained worthwhile response; severe disabilities during "on" periods being the major problem. Subcutaneous apomorphine is proposed as an effective treatment for patients with incapacitating "off" period disabilities refractory to oral medication and should be considered before experimental implantation procedures.
\end{abstract}

The incidence of disabling "on-off" fluctuations increases with the duration of levodopa treatment and after ten years of sustained therapy most patients are affected. ${ }^{1}$ For the majority treatment is difficult. The use of selegiline, ${ }^{23}$ partial substitution of levodopa by orally administered dopamine agonists ${ }^{4}$ and controlled-release levodopa preparations ${ }^{56}$ may temporarily extend "on" periods in some patients. Subcutaneous apomorphine, a directly acting dopamine agonist with affinity for both D1 and D2 receptors, rapidly and consistently reverses the "off" period motor deficit. ${ }^{7}$

We have previously described our initial experience with either continuous subcutaneous infusion or intermittent parenteral injection of apomorphine in 19 patients with severe “on-off" fluctuations. ${ }^{9}$ Eleven patients treated with subcutaneous infusion showed marked and sustained improvement; mean "off" hours per day were reduced from 10.1 to 3.8 and during the remaining "off" periods the mean disability score fell. Comparable results were obtained in eight patients with less severe disabilities given intermittent injections. Other reports have supported these observations. ${ }^{10-12}$

We report our further experience in 57 patients with disabling levodopa related motor oscillations treated with subcutaneous apomorphine for periods up to 32 months.

The effects of apomorphine in patients with additional disabilities including biphasic dyskinesias, urinary dysfunction and "off" period pain, dystonia, dyspnoea, anismus and belching have also been studied.

\section{Patients and methods}

Fifty seven levodopa treated patients with idiopathic Parkinson's disease were treated with apomorphine. In all cases disabling "onoff" fluctuations in motor performance remained despite attempts to improve control by redistribution of levodopa doses, concurrent use of dopamine agonists $(57 \%)$ or selegiline $(91 \%)$, controlled release levodopa preparations $(10 \%)$, and dietary protein restriction. Their mean age was 58.9 years and disease duration 15.9 years. All patients were admitted to hospital for pre-treatment assessment and instruction in the use of subcutaneous injection or infusion techniques.

It was first established that patients had incapacitating fluctuations, despite optimally timed doses of levodopa, by both clinical observation and the use of self-scoring patient diaries. If necessary, oral challenges of levodopa after withdrawal of overnight medication was followed by assessment to determine the duration of motor response and quality of the "on" period.

Patients with significant cardiovascular, hepatic or renal pathology were excluded. No patients with current evidence of neuropsychiatric disturbance or dementia were included. Routine haematological and biфchemical indices were measured before therapy and thereafter at monthly intervals.

To avoid side-effects such as nausea, vomiting and postural hypotension, domperidone, ${ }^{13}$ a peripherally acting dopamine receptor

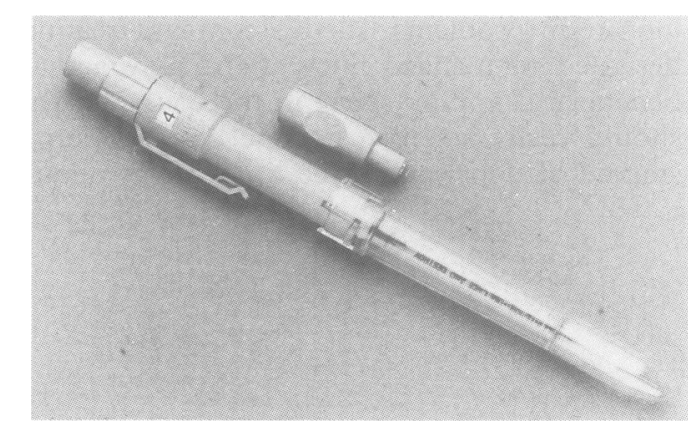

Figure 1 The 'Penject' multiple injection device. \\ Department of \\ Middlesex and \\ J P Frankel \\ PA Kempster \\ Neurology, The Middlesex \\ Hospital, Mortimer Street, \\ London W1N 8AA, United \\ Accepted 16 October 1989
}


antagonist (20 mg orally) was given two hours before a test dose of apomophine. One $\mathrm{mg}$ of apomorphine (apomorphine $\mathrm{HCl} 10 \mathrm{mg} / \mathrm{ml}$ ) was given subcutaneously during an "off" period, provoked by witholding levodopa medication. Incremental increases of $1 \mathrm{mg}$ of apomorphine every 20 minutes were then given until an unequivocal motor response occurred. This was defined as improvement in motor performance equivalent to that previously observed during the patient's "on" periods. Measurement of standing and sitting blood pressure was performed every ten minutes and for up to 40 minutes after the onset of the motor response.

Double the threshold dose was then given by intermittent subcutaneous injection from an insulin syringe mounted in a 'Penject' (Hypoguard Ltd, Melton, Suffolk) (fig 1). This facilitates the administration of several pre-set doses, can be conveniently carried by the patient and is easier to use for many patients than a conventional syringe alone. While remaining on their usual levodopa regime patients learned the technique of subcutaneous injection into the abdomen or thighs and were also taught to anticipate "off" periods. If this was not possible they were advised to inject themselves as soon as the "off" period had set in. Whenever possible spouses were also taught the technique. Most patients returned home within 10 days. With initial weekly outpatient reviews the process of education was continued and it was usually clear within a few weeks whether or not a patient was benefitting.

Patients whose overall control remained unsatisfactory but were known to have good "on" period response to single intermittent doses of apomorphine were transferred to continuous subcutaneous infusion by minipump.

The Graseby MS 26 (fig 2) or MS 16A syringe drivers (Graseby Medical Ltd, Watford, Herts) were used, the MS 26 is able to deliver apomorphine solution $(10 \mathrm{mg} / \mathrm{ml})$ up to $5 \mathrm{mg}$ per hour (by increments of $0.05 \mathrm{mg}$ per hour) and also provide bolus doses of $0.3 \mathrm{mg}$ (the MS 16A has a maximum rate of $25 \mathrm{mg} /$ hour, increments of $1.25 \mathrm{mg} /$ hour and bolus doses of $1.25 \mathrm{mg}$ ).

The delivery needle (Travenol Auto Syringe Microvolume Infusion Set-Cambridge Health Care Ltd, Cambridge, United Kingdom) was inserted subcutaneously into the abdominal wall and the site changed at least daily. Continuous infusion was started at a rate of $1 \mathrm{mg}$ per hour then increased according to the individual response each day. Patients were encouraged to make use of the booster function of the pump in anticipation of "off" periods. The basal rate of infusion and the size and frequency of bolus doses were titrated against the response, increasing the former to reduce severity and duration of "off" periods and the latter as a fine tuning to control remaining "offs". Whenever possible patients were encouraged to employ the bolus function rather than increasing the background continuous rate. Adjustment of the patients' levodopa regimes, by reducing the size and frequency of dose, was attempted once apomorphine treat-

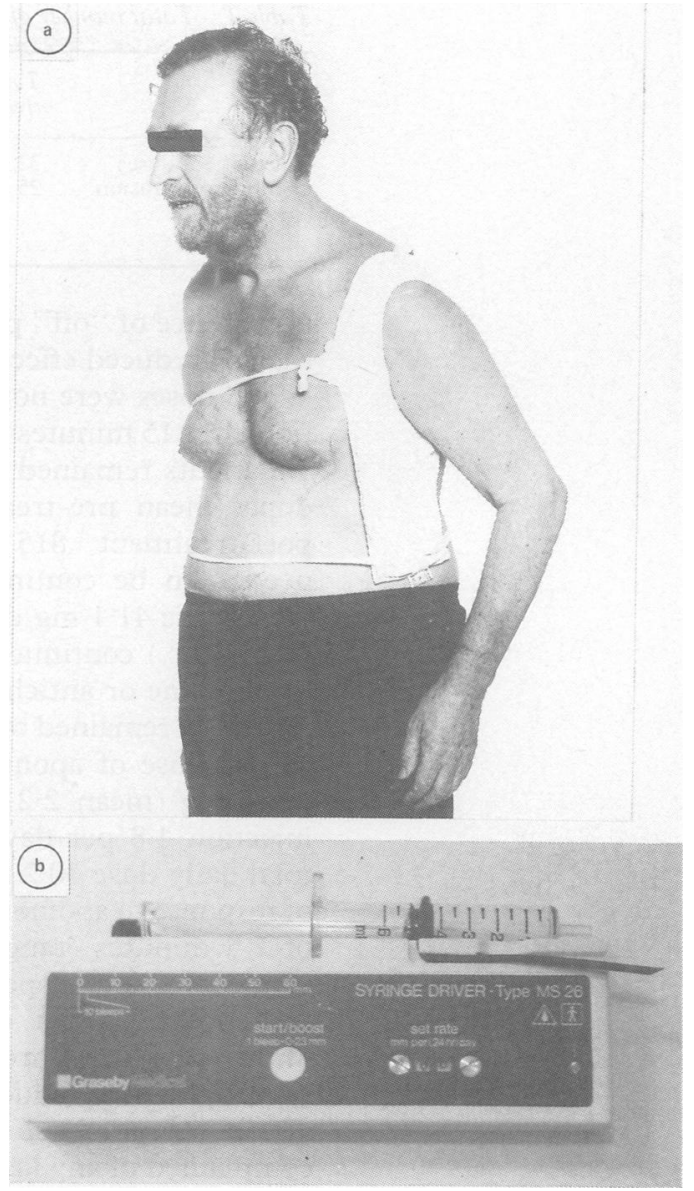

Figure 2 (a) The Graseby MS 26 syringe driver, (b) A patient with the driver in a shoulder holster, alternatively it can be carried in the pocket or from a belt.

ment was in progress. Statistical analysis was by Student's $t$ test with comparison of paired samples.

\section{Results \\ A. On-off oscillations \\ (i) Intermittent doses}

Thirty-two patients (19 men; 13 women), mean age 59.0 years (range $40-73$ ), were treated with multiple intermittent injections. Their mean duration of disease was 14.5 years (range 5-23), mean duration of levodopa therapy $12 \cdot 8$ years (3-20) and mean Hoehn and Yahr score $3.5(2-5)$.

Diary records in the first eight patients treated, showed a mean reduction in "off" hours from 6.0 to $2.7(p<0.01)$ shortly after starting apomorphine; at one year mean "off" hours was $3 \cdot 2$. The 30 patients who remained on long-term treatment were reviewed after a mean duration of 13.5 months (range 5-26). Total daily "off" hours fell from 6.9 before treatment to 2.9 ( $\mathrm{p}<0.02)$; this improvement has been maintained.

Individual injections of apomorphine, given during "off" periods, produced benefit subjectively equivalent to the levodopa "on" period motor response. Larger doses increased duration of action and the severity of dyskinesias. Some patients would vary the dose depending upon the severity of an "off" period. Dose failure was reported more often later in the day. This appeared to correlate with the increased 
Table 1 Total number of patients treated with both intermittent injection and continuous infusion

\begin{tabular}{lllll}
\hline & $\begin{array}{l}\text { Total number } \\
\text { treated }\end{array}$ & $\begin{array}{l}\text { Number of } \\
\text { early failures }\end{array}$ & $\begin{array}{l}\text { Number treated } \\
\text { long-term }\end{array}$ & $\begin{array}{l}\text { Number of } \\
\text { late failures }\end{array}$ \\
\hline $\begin{array}{l}\text { Intermittent doses } \\
\text { Continuous infusion }\end{array}$ & 32 (19 males, 13 females) & $\begin{array}{l}2 \text { (inter-dose dyskinesia) } \\
3 \text { (15 males, 10 females) }\end{array}$ & 30 & 0 \\
& & 1 (biphasic dyskinesia) & 21 & $\begin{array}{l}\text { (problem with pump } \\
\text { technique) } \\
1 \text { (hypotonia/mutism) }\end{array}$ \\
\hline
\end{tabular}

occurrence of "off" periods at that time rather than to reduced effectiveness of the injections. When doses were not adequate a repeat injection after 15 minutes usually produced benefit.

Patients remained on similar doses of levodopa (mean pre-treatment dose $854 \mathrm{mg} /$ day post-treatment $815 \mathrm{mg} /$ day). Domperidone needed to be continued in $60 \%$ of patients mean dose $41.1 \mathrm{mg} /$ day (range $10-60 \mathrm{mg}$ ), fifteen $(50 \%)$ continued to take bromocriptine, amantadine or anticholinergic medication and $12(40 \%)$ remained on selegiline $\mathrm{HCl}$.

The dose of apomorphine ranged between $0.2-5 \mathrm{mg}$ (mean $2.2 \mathrm{mg}$ ), mean frequency of injection 4.8 per day (range $2-18$ ) and mean total daily dose $10 \cdot 2 \mathrm{mg}(0 \cdot 8-27 \cdot 5)$. The onset of response to apomorphine began after a mean of 7.5 minutes (range $3 \cdot 5-12 \cdot 5$ ). Typically a single injection of apomorphine had a duration of action of about one hour (range 20-120 minutes). Thirty three per cent of the patients reported some reduction in the duration of action of apomorphine doses but only $13 \%$ complained of any loss of benefit. The reversal of motor deficit was often preceded by repeated yawning sometimes associated with somnolence especially during the first few days of treatment. Ten patients $(33 \%)$ used apomorphine at night to improve nocturnal akinesia or other "off" period disabilities.

\section{(ii) Continuous infusion}

Twenty-five patients ( 15 men; 10 women) have been treated by continuous subcutaneous infusion of apomorphine; mean age 58.8 years (range $40-74$ ), duration of disease $17 \cdot 8$ years (7-24) duration of levodopa therapy 15.6 years (3-20) and Hoehn and Yahr stage 4.1 (4-5). Twenty one continued on long-term treatment for up to 32 months, with little change in total daily apomorphine requirements. Infusion rates ranged between $1.25-5.5 \mathrm{mg} /$ hour (mean $3.3 \mathrm{mg} /$ hour), equivalent to $0.02-0.08 \mathrm{mg} / \mathrm{kg} /$ hour (mean $0.05 \mathrm{mg} / \mathrm{kg} /$ hour); with the majority of patients requiring between $2-4 \mathrm{mg}$ / hour. Patients supplemented the continuous infusion with an average of 9.5 bolus doses per day (range 0-32) at a mean dose of $2.4 \mathrm{mg}$ per bolus (range $1 \cdot 0-7 \cdot 5$ ). Onset of action following a booster dose was slightly slower in this group compared with those on intermittent in- jections, the mean delay being 9.0 minutes (range 5-15). The total daily dose for individual patients varied between 24 and $207 \mathrm{mg}$ (mean $89 \mathrm{mg} /$ day). Seven patients $(33 \%$ ) took apomorphine for 24 hours per day with no apparent loss of efficacy.

Diary records from the first 11 cases treated showed a fall in mean total "off" hours from 10.1 to 3.8 ( $p<0.01$ ); at one year. Review of the 21 patients who received long-term treatment (mean duration 22 months, range 5-32) showed a fall in mean total daily "off" hours from 9.9 to 4.5 ( $p<0.01$ ).

Levodopa requirements fell in over $60 \%$ of patients, irrespective of duration of treatment, with a mean reduction of $21.87 \%$ (from 992 to $775 \mathrm{mg} /$ day: nsp < 0.1); when the data for cases on treatment for over 18 months were analysed separately this reduction was $32 \%$ $(\mathrm{p}<0.02)$. Three patients were able to discontinue levodopa.

Seven patients $(33 \%)$ continued to require oral domperidone at a mean daily dose of $35 \mathrm{mg}$ the remainder were able to withdraw the drug without ill-effect. Ten remained on some form of oral antiparkinsonian medication other than levodopa: six taking anticholinergics, three bromocriptine, two amantidine and one selegiline $\mathrm{HCl}$. One patient elected to change back from continuous infusion to intermittent injection.

\section{B Dyskinesias}

Most patients had only moderately severe drug-induced involuntary movements during "on" periods. There were however four with disabling biphasic dyskinesias and nine with severe inter-dose involuntary movements. Biphasic dyskinesias initially responded favourably to both single injections and continuous infusions of apomorphine, but improvement was maintained for at most a few days after which dyskinesias broke through and eventually occurred almost continually during "on" periods. In five of the patients with severe inter-dose chorea it was possible to reduce the frequency and severity of drug-induced dyskinesia, by reducing the frequency and size of levodopa doses and treating the resulting increase in "off" periods with appropriately

Table 2 Daily "off" hours, apomorphine and levodopa requirements before treatment and on long-term follow up.

\begin{tabular}{|c|c|c|c|c|c|c|}
\hline & \multirow{2}{*}{$\begin{array}{l}\text { Mean duration } \\
\text { of treatment } \\
\text { months } \\
\text { (range) }\end{array}$} & \multicolumn{2}{|c|}{ Total daily "off" hours } & \multicolumn{2}{|c|}{ Mean total daily levodopa dose, $\mathrm{mg}$} & \multirow{2}{*}{$\begin{array}{l}\text { Mean total daily } \\
\text { apomorphine dose, } \\
\text { mg (range) }\end{array}$} \\
\hline & & $\begin{array}{l}\text { Before } \\
\text { treatment }\end{array}$ & $\begin{array}{l}\text { After } \\
\text { treatment }\end{array}$ & $\begin{array}{l}\text { Before } \\
\text { treatment }\end{array}$ & $\begin{array}{l}\text { After } \\
\text { treatment }\end{array}$ & \\
\hline $\begin{array}{l}\text { Intermittent injection } \\
(\mathrm{n}=30)\end{array}$ & $\begin{array}{l}13 \cdot 5 \\
(5-26)\end{array}$ & $6 \cdot 9$ & $2 \cdot 9^{\star}$ & 854 & 815 & $\begin{array}{l}10 \cdot 2 \\
(0.8-27 \cdot 5)\end{array}$ \\
\hline $\begin{array}{l}\text { Continuous infusion } \\
(n=21)\end{array}$ & $(5-32)$ & 9.9 & $4 \cdot 5^{\star \star}$ & 992 & 775 & $\begin{array}{l}89 \\
(24-207)\end{array}$ \\
\hline
\end{tabular}

${ }^{\star} \mathrm{p}<0.02 ;{ }^{\star \star} \mathrm{p}<0.01$ 
timed doses of apomorphine. However, worthwhile improvement was not always possible particularly when this feature alone had been the main incapacity. In two patients in whom it was not possible to reduce dyskinesia severity they elected to continue occasional apomorphine injections to treat particularly severe "off" episodes, when conversion to a dyskinetic state was felt to be preferable. One, of four treated, with biphasic dyskinesias remained on apomorphine, using single injections approximately once per day to provide a rapid and reliable "on" usually in the late afternoon when their response to levodopa had been unpredictable.

\section{Positive "off" period phenomena}

Injections of apomorphine were useful in terminating other parkinsonian disabilities. Two patients with "off" period functional bladder outlet obstruction ${ }^{14}$ benefited from appropriately timed injections; three with parkinsonian obstructive defaecation (anismus $)^{1516}$ were able to empty their bowels more effectively; three with severe "off" period limb and pelvic pain and two with early morning dystonia responded promptly; two suffering from distressing paroxysmal belching during “off" periods ${ }^{17}$ resistant to oral levodopa found that appropriately timed doses almost completely suppressed the symptom; and one man with "off" period hallucinations responded well to intermittent injection. We also gave apomorphine infusions to two patients with advanced disease who had critically deteriorated; in one precipitated by a chest infection and in the other following a profound depressive illness when the patient had discontinued levodopa. Both were in extremis with generalised rigidity, akinesia and fever despite maximal tolerated doses of levodopa. They were given apomorphine and the dose gradually increased up to $14 \mathrm{mg}$ per hour. Both responded well.

\section{Treatment failures}

Two patients with marked inter-dose dyskinesia on levodopa were withdrawn from treatment with intermittent doses of apomorphine because of a worsening of their involuntary movements. Four patients (on continuous infusion) initially thought suitable were withdrawn from treatment because of side effects; in three because of an unacceptable increase in biphasic dyskinesias and hallucinations in the other. Late withdrawal of treatment was necessary in two of the 21 patients, on subcutaneous infusion, whose initial response was satisfactory. The first had marked oscillations in motor function with severe inter-dose dyskinetic movements on levodopa. With apomorphine significant improvement in overall mobility was achieved in hospital but this could not be maintained at home. She was unable to cope with the technique and returned to conventional drug therapy. A second patient with initial sustained benefit developed late hypotonia and mutism.

\section{E Adverse reactions}

\section{(i) Cutaneous}

All patients on continuous infusions developed nodules at the needle sites. Severity was related to the total daily dose of apomorphine. In three patients infusion site nodules became infected requiring incision and drainage. Excessive bleeding from the needle site immediately after insertion occurred in a patient who had von Willebrand's disease; a second patient bled profusely from an old infected abdominal infusion site (with a particularly severe nodular reaction) and required blood transfusion. Intermittent injections caused itchy nodules in a minority of patients.

\section{(ii) Neuropsychiatric}

Visual hallucinations and confusion occurred in three patients, on continuous apomorphine infusions. After six months of treatment, a 60 year old woman complained of seeing small worms on her food and in her home, these symptoms resolved when her apomorphine was reduced. A 67 year old man experienced visual pseudo-hallucinations which had previously occurred when taking levodopa and a 62 year old man, given a trial of apomorphine, developed paranoid ideas and complained of seeing animals and people. His mental state returned to normal on withdrawal of treatment. Also a 67 year old woman with severe disability, who had responded favourably for over six months on continuous infusion, became gradually more disabled by hypotonia during "on" periods. She then became increasingly paranoid and withdrawn, and later mute. Both levodopa and apomorphine were withdrawn in turn without improvement.

Three patients with histories of psychosis on other antiparkinsonian medication were not affected.

\section{(iii) Other symptoms}

Most patients initially experienced mild drowsiness usually accompanied by yawning but this persisted only in two. Many reported occasional nausea in relation to apomorphine injections and postural hypotension was encountered on two occasions, this was usually attributable to the omission of domperidone.

A 62 year old man consistently noticed a generalised unpleasant sensation following apomorphine injections which he had not experienced after doses of levodopa producing a comparable benefit. Two patients described rhinorrhoea and increased lacrimation shortly after injections; one had previously noted the same phenomena after levodopa.

A 58 year old man, complained of reduced facial hair growth and loss of libido after starting treatment with intermittent injections of apomorphine. On the other hand, a 64 year old man became embarrassingly hyperlibidinous.

An overdose of apomorphine occurred in a 62 year old man on a continuous infusion. His wife accidentally injected subcutaneously about $25 \mathrm{mg}$ of apomorphine. After three minutes he felt faint, nauseated, lost consciousness and recovered within 20 minutes. He was then found to be alert with a pulse rate of 40 /minute 
and his supine blood pressure was $90 / 50 \mathrm{~mm}$ $\mathrm{Hg}$. He recovered completely within an hour. One patient broke a needle during injection and the fragment remains in the subcutaneous tissue.

\section{(iv) Laboratory investigations}

Peripheral blood eosinophilia of up to 10 per cent occurred shortly after starting therapy in all patients treated by continuous infusion; this returned to normal in about half of the patients treated for over one year. Other haematological indices, including plasma urea and creatinine concentrations remained normal.

A 44 year old woman on treatment with levodopa for 12 years and apomorphine for 28 months developed an autoimmune haemolytic anaemia with a positive Coomb's test; the agglutinating antibody was identified as IgG. This picture was typical of that described in levodopa induced autoimmune haemolytic anaemia. ${ }^{1819}$

\section{Discussion}

Subcutaneous apomorphine has led to a sustained marked improvement in a selected group of parkinsonian patients hitherto disabled by refractory and severe "off" period disabilities. Providing a patient's "on" response to levodopa is not marred by severe dyskinesia, hypotonia or psychotoxicity, apomorphine is usually beneficial, improving the quality of life and often restoring functional independence. Although it may be possible to diminish dyskinesias by giving apomorphine with concomitant reduction of levodopa, we have found the antiparkinsonian effects of apomorphine and levodopa to be strikingly similar and have been unable to confirm the specific anti-dyskinetic effects reported by Duby and colleagues. ${ }^{20}$ When inter-dose dyskinesia persists, it is the overall improvement when compared with the "off" period motor state which determines the success of treatment. This also depends on the patient understanding the rationale for using apomorphine and his or her ability to anticipate or at least identify "off" periods. Our usual strategy is, to first treat with intermittent injections only changing later to continuous minipump infusion if oscillations remain prominent. In most cases the former regime is found to be adequate.

In only three cases was it possible to achieve stable control on apomorphine without levodopa. This was not because apomorphine was weaker than levodopa but because the doses and therefore volumes of solution needed for monotherapy led to problems with skin nodules.

In general, apomorphine was well tolerated with relatively few side effects and no significant tolerance to the therapeutic antiparkinsonian effect was seen. On the other hand, tachyphylaxis to nausea and postural hypotension occurred rapidly. Reversible neuropsychiatric toxicity was uncommon. It may be that psychotoxic effects seen more frequently with other dopamine agonists occur as a result of different actions on dopamine receptor sub- types or other transmitter systems or perhaps apomorphine has intrinsic anti-psychotic activity, ${ }^{21}$ possibly from the piperidine moiety of the molecule. ${ }^{22}$

Intermittent injections may also be useful in treating a variety of isolated "off" period problems such as pain, dystonia, voiding dysfunction, anismus, hallucinosis, backache and belching. ${ }^{14-17} \mathrm{We}$ consider some of these phenomena to be directly related to sustained levodopa therapy and not simply a return of former parkinsonian disability. Our experience with two patients with critical deterioration as a result of intercurrent illness suggests that there may be an emergency role for subcutaneous apomorphine including the management of the levodopa withdrawal syndrome which closely resembles the "neuroleptic malignant syndrome". Finally an apomorphine challenge, after domperidone pre-treatment, may prove to be a useful quick test for dopaminergic responsiveness. ${ }^{23}$

These clinical observations using apomorphine may have some bearing on understanding the mechanism of the motor response to levodopa. The exact mode of action of levodopa is disputed but it has been suggested that presynaptic conversion to dopamine and intraneuronal storage are essential to its action. ${ }^{1}$ Even if therapeutic responses to levodopa are not dependent on synaptic release of dopamine by surviving nigro-striatal terminals, these terminals are the major sites of dopamine formation from exogenous levodopa in the striatum. ${ }^{24}$ Apomorphine while possessing both $\mathrm{D} 1$ and $\mathrm{D} 2$ receptor agonist properties does not share transport or metabolic pathways with levodopa. Although in intact experimental animals, administration of apomorphine suppresses the rate of firing of nigro-striatal cells ${ }^{25}$ and in low dose has been found to produce a reduction in locomotor activity, thought to represent pre-synaptic inhibition of endogenous dopamine release, its actions on parkinsonian motor disability are likely to be mediated totally at post-synaptic receptor sites.

Comparison therefore of motor responses to levodopa and apomorphine may be relevant in trying to elucidate the mechanism of different degrees of levodopa responsiveness between individual parkinsonian patients. If impaired responsiveness is due to pre-synaptic changes in nigro-striatal terminals, differences in responsiveness to levodopa and apomorphine might be expected; whereas similarity in the pattern and magnitude of levodopa and apomorphine responses would suggest that differences in post-synaptic receptors cause differences in responsiveness. Our findings support the latter, but we have only looked at patients with prolonged disease duration who have either developed symptomatic motor oscillations or other problems during medium or long term treatment, we have not done comparative levodopa/apomorphine studies on untreated patients or those treated for a short time.

However, these considerations may still be of relevance to the practical long term management of parkinsonian patients with levodopa or 
dopamine agonist medication. If limitations in drug responsiveness are caused by striatal postsynaptic factors such as loss of receptor numbers or sensitivity, and motor responses to levodopa and apomorphine are equivalent in individual patients, it follows that the quality of "on" phase motor function on levodopa therapy is unlikely to be surpassed by other antiparkinsonian agents acting on the dopaminergic system. The maximum expected benefit from treatment with levodopa or dopamine agonist medication would be to maintain individual patients in "on" states for the greatest proportion of the time. If the difference between "on" and "off" phase motor function is small, especially when the degree of disability is large, use of dopamine agonist therapy in conjunction with drug delivery technology (including subcutaneous delivery of apomorphine) or of surgical techniques to deliver levodopa or dopamine directly into the brain or CSF is unlikely to produce significant benefit.

Despite these reservations it seems likely that the duration of effective medical treatment can be significantly extended for many patients. These results also suggest that a search should continue for a long-acting powerful orally administered dopamine receptor agonist with a pharmacological profile similar to apomorphine. In the meantime the use of parenteral apomorphine provides an effective safe way of diminishing disabling "off" periods in levodopa treated patients.

This paper was presented at the 41 st annual meeting of the American Academy of Neurology, Chicago, April 1989.

PAK and JPF were Kate Stillman Research Fellows. Support was also provided by the Parkinson's Disease Society of Great Britain. We thank Diana Wade and Jenny Wooten of the North Middlesex Hospital Sterile Production Unit for preparation of the apomorphine solution.

1 Marsden CD, Parkes JD, Quinn N. Fluctuations of disabilities in Parkinson's disease-clinical aspects. In: Marsden CD, Fahn S, eds. Movements disorders. London: Butterworths, 1982;96-122.

2 Birkmayer W, Riederer P, Ambrozi L, Youdim MBH. Implications of combined treatment with madopar and L- deprenyl in Parkinson's disease. Lancet 1977;ii:439-43.

3 Lees AJ, Shaw KM, Kohout LJ, et al. Deprenyl in Parkinson's disease. Lancet 1977;ii:791-6.

4 Hoehn MM, Elton RL. Low dosages of bromocriptine added to levodopa in Parkinson's disease. Neurology 1985;35:199-206.

5 Nutt JG, Woodward WR, Carter JH. Clinical and biochemical studies with controlled-release levodopa/ carbidopa. Neurology 1986;36:1206-11.

6 Pezzoli G, Tesei S, Ferrante C, Cossutta E, Zecchinelli A Scarlato G. Madopar HBS in fluctuating parkinsonian patients: two-year treatment. Movement Disorders 1988 3:37-45.

7 Hardie RJ, Lees AJ, Stern GM. On-off fluctuations in Parkinson's disease. A clinical and neuropharmacological study. Brain 1984;107:487-506.

8 Corsini GU, Del Zompo M, Gessa GL, Mangoni A. Therapeutic efficacy of apomorphine combined with an extracerebral inhibitor of dopamine receptors in Parkinson's disease. Lancet 1979;i:954-6.

9 Stibe CMH, Kempster PA, Lees AJ, Stern GM. Subcutaneous apomorphine in parkinsonian on-off oscillations. Lancet 1988;i:403-6.

10 Poewe W, Kleedorfer B, Gerstenbrand F, Oertel W. Subcutaneous apomorphine in Parkinson's disease. Lancer cutaneous

11 Chaudhuri KR, Critchley P, Abbott RI, Pye IF, Millac $\mathrm{PAH}$. Subcutaneous apomorphine for on-off oscillations in Parkinson's disease. Lancet 1988;ii: 1260.

12 Pollak P, Champay AS, Hommel M, Perret JE, Benabid AL Subcutaneous apomorphine in Parkinson's disease. $J$ Neurol Neurosurg Psychiatry 1989;52:544.

13 Agid Y, Pollak P, Bonnet AM, Signoret JL, Lhermitte F. Bromocriptine associated with a peripheral dopamine blocking agent in treatment of Parkinson's disease. Lancet 1979;i:570-2.

14 Christmas TJ, Kempster PA, Chappel CR, Frankel JP, Lees AJ, Stern GM, Milroy EJG. Role of subcutaneous apomorphine in parkinsonian voiding dysfunction. Lancet apomorphine in

15 Mathers SE, Kempster PA, Swash M, Lees AJ. Constipation and paradoxical puborectalis contraction in anismus and Parkinson's disease: a dystonic phenomenon? J Neurol Neurosurg Psychiatry 1988;51:1503-7.

16 Mathers SE, Kempster PA, Law P, Frankel JP, Bartram C, Lees AJ, Stern GM, Swash M. Anal sphincter dysfunction in Parkinson's disease. Arch Neurol 1989;46:1061-4.

17 Kempster PA, Lees AJ, Crichton P, Frankel JP, Shorvon P. Off-period belching due to a reversible disturbance of oesphageal motility in Parkinson's disease and its treatment with apomorphine. Movement Disorders $1989 ; 4$ : $47-52$.

18 Territo MC, Peters AW, Tanaka KR. Autoimmune hemolytic anemia due to levodopa therapy. JAMA 1973; 226:1347-8.

19 Lindstrom FD, Lieden G, Engstrom MS. Dose-related levodopa-induced haemolytic anaemia. Ann Int Med 1977;83:298-300.

20 Duby SE, Cotzias GC, Papavasiliou PS, Lawrence WH. Injected apomorphine and orally administered levodopa in parkinsonism. Arch Neurol 1972;27:474-80.

21 Corsini GU, Pitzalis GF, Bocchetta A, Del Zompo M. The use of dopamine agonists in the treatment of schizophrenia. Neuropharmacology 1981;20:1309-13.

22 Cotzias GC, Papavasiliou PS, Tolosa ES, Mendez JS, BellMidura M. Treatment of Parkinson's disease with aporphines; possible role of growth hormone. $N$ Eng J Med 1976;294:567-72.

23 Barker R, Duncan J, Lees A. Subcutaneous apomorphine as a diagnostic test for dopaminergic responsiveness in
parkinsonian syndromes. Lancet 1989;i:675.

24 Melamed E. Mechanisms of action of L-dopa. In: Koller W, ed. Handbook of Parkinson's disease. New York: Dekker, 1987:355-70.

25 Bunney BS, Aghajanian GK, Roth RH. Comparison of effects of L-dopa, amphetamine and apomorphine on firing rate of rat dopaminergic neurones. Nature New Biology 1973;245:123-5 